\title{
A contribuição da Geofísica em projetos de sequestro geológico de $\mathrm{CO}_{2}$
}

Jorge Fiori Fernandes Sobreira (PETROBRAS/ CENPES) Rodolfo Dino (PETROBRAS/ CENPES)

Copyright 2014, SBGf - Sociedade Brasileira de Geofísica

Este texto foi preparado para a apresentação no VI Simpósio Brasileiro de Geofísica, Porto Alegre, 14 a 16 de outubro de 2014. Seu conteúdo foi revisado pelo Comitê Técnico do VI SimBGf, mas não necessariamente representa a opinião da SBGf ou de seus associados. É proibida a reprodução total ou parcial deste material para propósitos comerciais sem prévia autorização da SBGf.

\section{Resumo}

Questões relacionadas à agressão ao Meio Ambiente por ação antropogênica têm levado a Comunidade Internacional a debater e a propor mecanismos de desenvolvimento limpos (clean development mechanisms) como forma de prevenir ou mitigar impactos à Natureza e ao ser humano. A Indústria de Petróleo, em particular, enquanto potencial emissora de gases causadores do efeito-estufa - tais como o $\mathrm{CO}_{2}$ - é uma das que mais têm se mobilizado no sentido de implementar medidas diversas e de fomentar investigações e pesquisas que possibilitem o mais adequado gerenciamento deste tipo de emissão. Embora o Brasil não tenha ainda uma legislação ou regulamentação específica sobre o assunto, algumas instituições e empresas vêm se antecipando, através da proposição e condução pioneira de projetos de pesquisa, e este é o caso da PETROBRAS. Uma das alternativas para a redução das referidas emissões é o sequestro geológico do $\mathrm{CO}_{2}$ em subsuperfície, preferencialmente em reservatórios naturais do tipo aquíferos salinos profundos, o que implica riscos praticamente nulos de impactos ao consumo humano. Projetos deste tipo têm a Geofísica, em seus diversos métodos, como uma disciplina essencial em todas as suas fases, desde a escolha de alvos para o armazenamento permanente do $\mathrm{CO}_{2}$ propriamente dito até o monitoramento da integridade do mesmo ao longo de um período de tempo suficientemente longo para atender requisitos legais e regulatórios. Um atrativo adicional que projetos deste tipo podem ter é a habilitação ao recebimento de créditos de carbono, um mercado emergente no Mundo.

No presente trabalho é sumarizada a metodologia desenvolvida na PETROBRAS visando ao sequestro geológico de $\mathrm{CO}_{2}$, como atividade acessória às suas atividades de Exploração e Produção, destacando-se a contribuição dos métodos geofísicos.

\section{Introdução}

Gases como $\circ \mathrm{CO}_{2}$ constituem algumas das principais emissões das companhias de petróleo ao meio externo. Alguns dos campos de petróleo descobertos pela PETROBRAS no offshore possuem concentrações não desprezíveis destes gases, que, uma vez produzidos, juntamente com o hidrocarboneto de interesse, exigem o adequado tratamento para evitar 0 seu escape em proporções indesejáveis para a atmosfera. Embora parte deste gás possa ser reaproveitada em processos de melhoria da produção, através de sua reinjeção no próprio reservatório produtor, uma alternativa se apresenta de injetá-lo em reservatórios naturais profundos (aquíferos salinos) ou ainda em reservatórios de gás depletados (nos quais a repressurização ocasionada por tal injeção acarrete riscos menores à integridade do armazenamento/ trapeamento). Neste caso está se falando do sequestro geológico de $\mathrm{CO}_{2}$, iniciativa em investigação pela PETROBRAS, que vem desenvolvendo uma metodologia a respeito.

Entende-se por sequestro geológico do $\mathrm{CO}_{2}$ em subsuperfície o trapeamento permanente (ou de fato, empreendido em uma escala de tempo suficientemente longa para prevenir riscos de escape imediatos) deste gás em rochas sedimentares porosas que representem reservatórios naturais, como é o caso de antigos reservatórios produtores depletados em hidrocarbonetos gasosos e de aquíferos situados a profundidades tais que a água de formação neles contida seja considerada inaproveitável (salina) para os padrões de consumo humano, e assim sem perspectivas de utilização, ao menos num futuro próximo. Eventualmente, o sequestro geológico pode também se valer de reservatórios artificialmente criados, como é o caso das cavernas de sal. O processo de armazenamento do $\mathrm{CO}_{2}$ em subsuperfície é antes complexo, e envolve mecanismos de trapeamento tanto mecânicos (que tendem a prevalecer no curto a médio prazo) quanto químicos (oriundos do desequilíbrio causado pela injeção do $\mathrm{CO}_{2}$, e que tendem a se manifestar no médio a longo prazo) - figura 1. Em especial, considera-se o chamado "trapeamento mineral" (isto é, a formação de minerais carbonáticos a partir de precipitação química nos espaços porosos da rocha) como o mecanismo mais efetivo de trapeamento, e assim como aquele que acarreta menor risco de escape do gás para a superfície.

Nas condições de pressão e de temperatura naturais esperadas em subsuperfície, assume-se que $\mathrm{O}^{\mathrm{CO}_{2}}$ injetado deverá assumir um estado supercrítico, o que tende a favorecer 0 armazenamento de maiores volumes.

\section{Metodologia}

Um típico projeto de sequestro geológico do $\mathrm{CO}_{2} \mathrm{em}$ subsuperfície inclui várias etapas, que no geral compreendem:

a) a identificação e caracterização inicial de alvos para sequestro, segundo uma análise regional da área-alvo. Nesta etapa os métodos geofísicos, e em especial a Sísmica, tornam-se essenciais para permitir este tipo de reconhecimento, que deve ser suportado, na medida do possível, por informações diretas, tais como aquelas provenientes de poços exploratórios. Nesta fase os alvos são identificados a partir de uma sistemática semelhante àquela empregada na seleção de alvos para hidrocarbonetos (buscando fechamentos estruturais, por exemplo), embora 
devidamente adaptada para este caso, sendo posteriormente catalogados com relação às suas características mais relevantes. A busca por tais alvos é balizada por prévias estimativas dos volumes requeridos do montante de gás que se deseja sequestrar;

b) o ranqueamento destes alvos, tomando-se por base critérios técnicos (tais como a capacidade/ volume poroso disponível e a retenção/ eficácia do trapeamento) e econômicos (envolvendo custo, tais como a distância desde os pontos emissores e a profundidade onde irá se injetar $0 \mathrm{CO}_{2}$ ). Nesta etapa mais uma vez, a Geofísica, e em especial a Sísmica, contribui de maneira relevante, especialmente na avaliação de volumes, sempre que possível em conjunto com informações diretas;

c) a caracterização complementar dos alvos priorizados na etapa anterior, que deve incluir o estabelecimento do modelo geológico tridimensional do reservatório (caracterização geológica, onde mais uma vez a Geofísica contribui, especialmente na inversão para propriedades permoporosas a partir de dados sísmicos), a modelagem dos efeitos geomecânicos relacionados à injeção e consequentes riscos à integridade da acumulação (caracterização geomecânica), de acordo com a pressão de injeção, e a simulação numérica da injeção (modelagem numérica de fluxo). Esta etapa é desejavelmente complementada por uma quantificação de incertezas (para os cálculos volumétricos) e uma análise qualitativa e quantitativa dos fatores de risco do escape do gás (a própria injeção do $\mathrm{CO}_{2}$ e subsequente aumento de pressão interna do reservatório sendo um deles);

d) o processo de injeção propriamente dito, a partir dos poços injetores definidos com base nos resultados da etapa anterior;

e) a verificação sistemática da integridade do trapeamento do $\mathrm{CO}_{2}$ em subsuperfície, a partir do monitoramento por métodos diretos (poços de observação, por exemplo) e indiretos (por exemplo, empregando métodos geoquímicos e geofísicos), visando a detectar precocemente potenciais escapes para a superfície, permitindo assim a tomada de decisões e a implementação das ações cabíveis a tempo. Nesta etapa, métodos geofísicos diversos, de superfície ou de poço, podem e devem ser empregados de maneira desejavelmente integrada, para aprimorar a detecção da movimentação de fluidos em subsuperfície relacionada à injeção do $\mathrm{CO}_{2}$. Este é o caso, em especial, do método sísmico (identificação de contrastes de impedância acústica), do método eletromagnético (identificação de contrastes de resistividade elétrica), e, secundariamente, de outros métodos, como o gravimétrico (identificação de contrastes de densidade), elétrico (identificação de contrastes nas propriedades elétricas de maneira geral) e a interferometria por satélites - InSAR ou Interferometric synthetic aperture radar - este capaz de identificar sutis deslocamentos da superfície do terreno em resposta às variações da pressão interna em subsuperfície, por sua vez relacionadas à injeção do $\mathrm{CO}_{2}$. Este último método tem aplicação essencialmente no ambiente onshore.

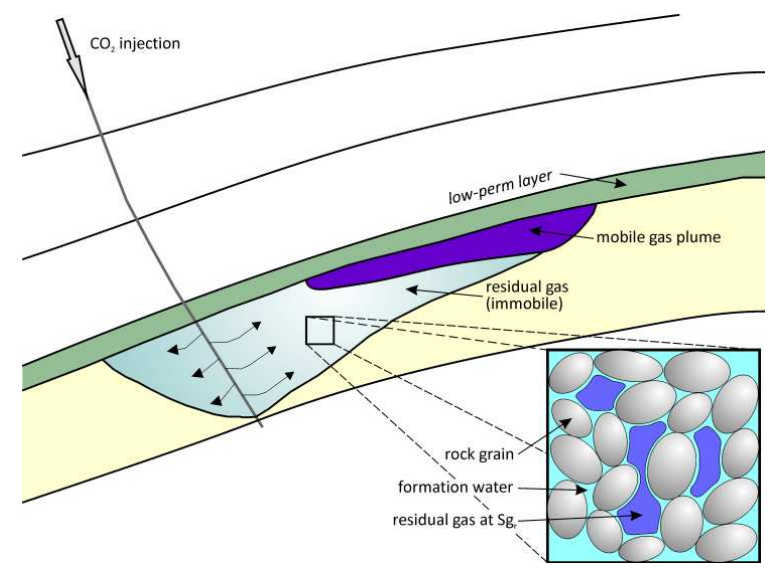

Figura 1 - Representação de um dos principais mecanismos mecânicos de trapeamento geológico de $\mathrm{CO}_{2}$ conhecido como "Migration assisted storage" (extraído de Juanes et al., 2006), segundo o qual gás residual (Sgr)é aprisionado no espaço poroso do reservatório após o "rebote" gravitacional da frente de água, em resposta à dissipação da pressurização inicial do aquífero promovida pela injeção do gás, enquanto uma pluma de gás (móvel) migra ascendentemente contra uma barreira de permeabilidade sobreiacente

\section{Resultados}

A PETROBRAS desenvolveu uma metodologia própria, conquanto calcada nas melhores práticas conhecidas, para a identificação e caracterização inicial, ranqueamento e caracterização complementar de alvos para futuro sequestro geológico do $\mathrm{CO}_{2}$ em subsuperfície, num primeiro momento com foco em áreas offshore. Tal metodologia é baseada na integração de dados de diferente natureza e em uma abordagem conservadora, de modo a evitar estimativas volumétricas excessivamente otimistas e pouco realistas. A partir da aplicação desta metodologia, diversos alvos foram identificados e catalogados, e alguns deles foram priorizados (a partir do seu ranqueamento com base em critérios técnicos e de custo) para posterior caracterização complementar, em um trabalho de natureza essencialmente multidisciplinar, envolvendo Geologia, Geoengenharia, Geomecânica e Geofísica. A figura 2 exemplifica um destes alvos, identificado com base na interpretação de dados sísmicos integrada à análise de dados diretos, de poço. 


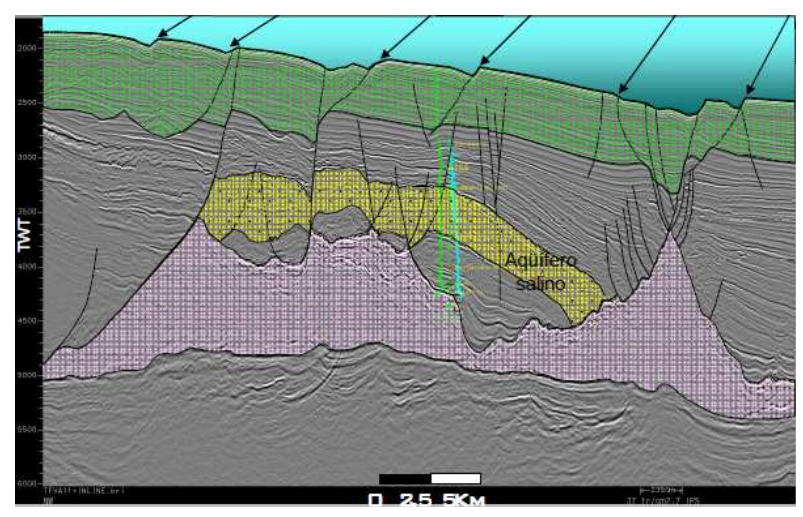

Figura 2 - Exemplo de alvo identificado em bacia da margem leste brasileira (intervalo em cor amarela) para fins de sequestro geológico do CO2; horizontes e falhas interpretados em seção sísmica em tempo; as falhas existentes não necessariamente representam risco de escape do $\mathrm{CO}_{2}$ para a superfície, cuja avaliação depende de estudo geomecânico

\section{Discussão e Conclusões}

$\begin{array}{clll}\text { A } & \text { PETROBRAS desenvolveu uma } \\ \text { metodologia interna para a identificação e }\end{array}$ caracterização de alvos para fins de sequestro geológico do $\mathrm{CO}_{2}$ em subsuperfície. A Geofísica se faz presente como uma disciplina essencial, com destaque para o Método Sísmico, que contribui fortemente na etapa inicial do projeto. Por outro lado, na etapa final de um típico projeto de sequestro geológico $\mathrm{CO}_{2}$, que vem a ser a de verificação da integridade do armazenamento em subsuperfície e prevenção de escape para a superfície, os diferentes métodos geofísicos, empregados de maneira integrada (métodos sísmico, eletromagnético, gravimétrico, elétrico e de interferometria por satélite) constituem certamente a principal ferramenta para a detecção precoce de riscos deste escape. Nos países onde já existe regulamentação a respeito, esta fase de verificação e monitoramento dura tipicamente algumas décadas, período ao longo do qual o monitoramento geofísico se faz necessário para 0 adequado gerenciamento do projeto de sequestro. Assim, a Geofísica, e em especial a Sísmica, torna-se essencial na identificação e caracterização de alvos potenciais para sequestro geológico do $\mathrm{CO}_{2}$, através da interpretação de dados sísmicos disponibilizados pela área de E\&P. Na fase posterior de verificação da integridade do armazenamento do $\mathrm{CO}_{2}$, novamente a Geofísica será demandada, devendo constituir-se na principal ferramenta de monitoramento, neste caso não apenas sísmico (Sísmica 4D) como também por métodos não-sísmicos, como os eletromagnéticos, elétricos e gravimétricos. Uma comparação destes métodos é apresentada na tabela I.

A Sísmica Multicomponente, a partir da interpretação conjunta de dados de onda PP e PS, é vista como capaz de agregar um valor ainda maior a projetos deste tipo, tanto na fase de identificação de alvos (especialmente na caracterização da rocha-reservatório e da rocha selante) como no monitoramento posterior.

O desenvolvimento deste projeto na PETROBRAS permitiu maximizar o valor da informação, ao possibilitar, por exemplo, aproveitarem-se como candidatos ao armazenamento geológico de $\mathrm{CO}_{2}$ para fins de sequestro permanente tanto prospectos exploratórios secos (ou com baixo potencial econômico) como reservatórios aquíferos de boa possança, identificados e confirmados por poços exploratórios,

\section{Agradecimentos}

Agradecimentos são devidos à PETROBRAS, por ter autorizado a publicação deste trabalho e por ter permitido o seu desenvolvimento.

\section{Referências}

Juanes, R., Spiteri, E. J., Orr Jr., F. M., Blunt, M. J.. Impact of relative permeability hysteresis on geological $\mathrm{CO}_{2}$ storage. Water Resouce Research, 42 


\begin{tabular}{|c|c|c|c|}
\hline $\begin{array}{l}\text { Método geofísico de } \\
\text { monitoramento }\end{array}$ & $\begin{array}{l}\text { Propriedade física } \\
\text { acessada }\end{array}$ & Prós & Contras \\
\hline $\begin{array}{l}\text { Sísmica de superfície 4D } \\
\text { (streamer) }\end{array}$ & \multirow[t]{4}{*}{$\begin{array}{l}\text { Impedância acústica (e } \\
\text { impedância cisalhante) }\end{array}$} & Sísmica de mais baixo custo & $\begin{array}{l}\text { - Menor robustez na extração da } \\
\text { impedância cisalhante } \\
\text { - Repetitividade baixa }\end{array}$ \\
\hline $\begin{array}{l}\text { Sísmica de superfície } 4 \mathrm{D} \\
\text { ( } O B C \text { não permanente) }\end{array}$ & & $\begin{array}{l}\text { - Maior robustez na extração da } \\
\text { impedância cisalhante } \\
\text { - Repetitividade média }\end{array}$ & Sísmica de custo médio a elevado \\
\hline $\begin{array}{l}\text { Sísmica de superfície } 4 \mathrm{D} \\
(O B C \text { permanente })\end{array}$ & & $\begin{array}{l}\text { - Maior robustez na extração da } \\
\text { impedância cisalhante } \\
\text { - Repetitividade superior }\end{array}$ & Sísmica de mais alto custo \\
\hline $\begin{array}{l}\text { Sísmica de poço } 4 \mathrm{D} \\
\text { (multicomponente) }\end{array}$ & & $\begin{array}{l}\text { - Maior robustez na extração da } \\
\text { impedância cisalhante } \\
\text { - Repetitividade superior }\end{array}$ & $\begin{array}{l}\text { Raio da imagem sísmica tipicamente } \\
\text { limitado a poucos } \mathrm{km} \text { em torno do poço } \\
\text { (o processamento interferométrico pode } \\
\text { aumentá-lo) }\end{array}$ \\
\hline $\begin{array}{l}\text { Sísmica } \begin{array}{r}\text { rasa (boomer, } \\
\text { sparker, } \\
\text { sonar) }\end{array} \\
\end{array}$ & $\begin{array}{l}\text { Refletividade, a partir } \\
\text { da qual se pode derivar } \\
\text { a impedância acústica }\end{array}$ & $\begin{array}{l}\text { De alta resolução, podendo ser útil } \\
\text { para identificar plumas de } \\
\text { exsudação/ vazamento na coluna } \\
\text { d'água }\end{array}$ & $\begin{array}{l}\text { De baixa capacidade de } \\
\text { inviável para imagear } \\
\text { profundos objetivonos }\end{array}$ \\
\hline $\begin{array}{l}\text { Gravimetria/ gradiometria } \\
\text { time lapse de fundo do } \\
\text { mar }\end{array}$ & \multirow[t]{2}{*}{ Densidade } & $\begin{array}{l}\text { Custo reduzido a médio, com } \\
\text { repetitividade média }\end{array}$ & $\begin{array}{l}\text { - Dificuldade operacional de } \\
\text { espalhamento dos sensores em lâmina } \\
\text { d'água elevada; } \\
\text { - Em processos de recuperação } \\
\text { melhorada tais como } W A G \text {, a anomalia } \\
\text { gravimétrica resultante tende a ser } \\
\text { neutralizada }\end{array}$ \\
\hline $\begin{array}{l}\text { Gravimetria/ gradiometria } \\
\text { time lapse de poço }\end{array}$ & & $\begin{array}{l}\text { Custo reduzido a médio, com } \\
\text { repetitividade superior }\end{array}$ & $\begin{array}{l}\text { Informação muito localizada no poço; } \\
\text { em processos de recuperação melhorada } \\
\text { tais como } W A G \text {, a anomalia gravimétrica } \\
\text { resultante tende a ser neutralizada }\end{array}$ \\
\hline $\begin{array}{l}\text { Eletromagnético time } \\
\text { lapse de fundo do mar }\end{array}$ & \multirow[t]{2}{*}{ Resistividade elétrica } & $\begin{array}{l}\text { - } \mathrm{O} \mathrm{CO}_{2} \text {, mesmo misturado com a } \\
\text { água da formação (ou o } \mathrm{HC} \text { ), tende } \\
\text { a preservar o caráter diferenciado da } \\
\text { resistividade (que faz diminuir a } \\
\text { resistividade do óleo); } \\
\text { - Repetitividade média }\end{array}$ & $\begin{array}{l}\text { Método não protagonista (necessita ser } \\
\text { integrado com outros métodos geofísicos) }\end{array}$ \\
\hline $\begin{array}{l}\text { Eletromagnético time } \\
\text { lapse de poço }\end{array}$ & & $\begin{array}{l}\text { - } \mathrm{O} \mathrm{CO}_{2} \text {, mesmo misturado com a } \\
\text { água da formação (ou o } \mathrm{HC} \text { ), tende } \\
\text { a preservar o caráter diferenciado da } \\
\text { resistividade (que faz diminuir a } \\
\text { resistividade do óleo); } \\
\text { - Repetitividade superior }\end{array}$ & $\begin{array}{l}\text { - Método não protagonista (necessita ser } \\
\text { integrado com outros métodos geofísicos) }\end{array}$ \\
\hline Elétrico (SP) time lapse & $\begin{array}{l}\text { Potencial elétrico/ } \\
\text { Intensidade da corrente } \\
\text { elétrica }\end{array}$ & $\begin{array}{l}\text { - De baixo custo, provendo } \\
\text { monitoramento em larga escala } \\
\text { - Não depende de fonte, mede } \\
\text { correntes elétricas relacionadas ao } \\
\text { fluxo de fluidos }\end{array}$ & $\begin{array}{l}\text { - De caráter coadjuvante com outros } \\
\text { métodos } \\
\text { - Sem histórico de aplicação no offshore }\end{array}$ \\
\hline
\end{tabular}

Tabela I - Comparação dos diferentes métodos geofísicos de monitoramento (de superfície de poço) que podem ser empregados durante o período de verificação da integridade do processo de armazenamento geológico do $\mathrm{CO}_{2}$ e respectivas propriedades físicas investigadas 